necessary for this plan of treatment, $I$ am at a loss to know, and yet some of our first and best accoucheurs boast that they use it in every case."-Dublin Quarterly Journal, August, 1849.

With this quotation, I dismiss the subject of Anæsthetic Midwifery, with the final remark, that in the facts this paper contains, I have offered a complete vindication of what has been called the à priori-i.e., the physiological-argument against anæsthesia in parturition. $A$ priori and à posteriori reasoning, have, at length, though travelling by different roads, met at the same point. But the à posteriori conviction has been obtained at a fearful cost. Thus, not to travel out of the record of this paper:-

Dr. Sachs refers to twelve cases of natural labour, in which anæsthesia was induced by ether.

Arrest of the pains was the common effect.

In one case, it became necessary to use the forceps in consequence. Metritis and death followed the anæsthetic and instrumental interference.

In one case, convulsions ensued.

Out of the twenty-seven chloroform cases-

In eighteen, more or less diminution of the uterine contrac tion was induced.

In four, there was laceration of the perinæum.

In one case, metritis followed.

In twelve, there were uttered groans and other manifestations of suffering, although the patients did not remember it on recovery.

In one case, puerperal convulsions occurred, and death in nineteen hours. In two others, there was ominous threatening of the same appalling catastrophe.

Such is the penalty paid for neglecting the foregone conclusions of physiology.

Such is the sacrifice to Empiricism !

Gloucester-terrace, Hyde Park, July, 1850.

\section{ON A CASE OF CONGENITAL PROTRUSION OF THE INTESTINES.}

BY W. M. FAIRBROTHER, M.D. Lond.

A Remarkable instance of congenital rupture occurred in my practice on the 29 th of June last. Upon the birth of a child, a large portion of intestine, about twenty-eight inches in length, was found protruding from the navel, dark and discoloured. It had evidently been out of place for many days. On my next visit, the bowels had acted, but were more protruded, with a considerable portion of the mesentery. I made a careful and limited incision downwards in the median line, and, with considerable trouble, reduced the intestine, and applied sutures and a compress. The child, however, died the same evening, with all the symptoms of strangulated hernia.

London-road, Southwark, July, 1850.

\section{fforeign 预epartment.}

\section{Chloroform in Neuralgia.}

Sown forms of neuralgia resist almost all the means used to subdue them, and anæsthetic agents may naturally be expected to be beneficial in such cases, both internally and externally. The Journal de Pharmacie gives the following formula for a chloroform ointment: chloroform, sixty drops; hog's lard, one ounce. Mix in a mortar, and use two or three frictions a day upon the painful spot. As this ointment turns yellow when exposed to the light; it should be placed in a coloured, widenecked, and well-stoppered bottle.

\section{Connexion between Gonorrhoea and Syphilis.}

Many practitioners, relying on imperfectly observed and erroneously explained facts, continue to regard gonorrhoea as capable of generating syphilis, in spite of the conclusive experiments of M. Ricord and his pupils. MT. DIDAX (of Lyons), anxious to prove the groundlessness of this opinion, has just proposed a prize of $£ 12$ to be awarded to the medical man who shall have sent in, before the first of August, 1851, ten well described cases of secondary syphilis arising from gonorrhoea. The cases must refer to men now alive, and residing in France. The patients must not have had, on the first of July, 1850, constitutional syphilis more than three years, and M. Diday will very probably keep his $£ 12$.
Homceopathy in Spain.

The homœopathic quackery is advancing in Spain. A royal decree has just been promulgated creating two homoepathic chairs in the faculty, one clinical and the other theoretical. The first will be filled by Dr. Rio, and the second by Dr. Nunez. This result is mainly attributable the weakness of the profession in Madrid, who had consented to public experiments being made, and who were hardly defending themselves from the inroads of the homceopathic tribe. A sort of trial of the virtues of homcopathy had been begun in Dr. Argumosa's wards, but as soon as the decree was made public, the followers of Hahnemann, having gained their end, dropped the experiments, the beginning of which pointed to an ultimate and disgraceful failure.

\section{Plugging by Insufflation.}

Dr. DiDAY, of Lyons, being called to a case of metrorrhagia which threatened to end fatally, had recourse to a new kind of plugging after the usual means had failed. He, namely, took a small bag of vulcanized india rubber, with which was connected a long and narrow tube. The bag having been compressed to a small size, and well greased, was introduced into the vagina, and filled with air by means of the tube. By being thus distended the caoutchoue bottle formed a sphere of about six inches in diameter, and the air was retained in it by tying its small extremity with a strong thread. The hæmorrhage ceased immediately, and after leaving the apparatus sixty-four hours in the vagina, the air was let out, and no hæmorrhagic symptom reappeared. Dr. Diday thinks this bag might be used, within the uterus, when dangerous hremorrhage occurs atter labour.

\section{Experiments on the Corpse of an Executed Culprit.}

Dr. Fexdmann has published a letter in L'Union Médicale, wherein he gives a description of some experiments which were very recently made by Professor Harless, of Munich, on the body of a culprit, fifty minutes after decapitation. These experiments were principally intended to verify those of Dr. Wagner on the contraction of the spleen, which this physiologist had performed upon animals.

Reaumur's thermometer, placed into the thorax immejiately the subject was brought in, by means of a small incision in an intercostal space, rose at once to $28^{\circ}$ (95 Fahrenheit). Whilst this was being done, Dr. Harless placed one wire of an electric machine, which had been prepared beforehand, into the divided spinal marrow, and the other on the skin of the shoulder; this produced directly vigorous contractions. Dr. Harless, without losing a moment, laid open the abdominal cavity, took out the spleen and placed it on a glass disk, in order to isolate it. Scarcely had the wire been plunged into that viscus than it rose in a few seconds like a bulwark around the wire. The same experiment was made upon other portions of the spleen with the same result, so that the contractility of that organ in the human subject could be looked upon as perfectly proved. The heart, when the thorax had been opened and the pericardium taken off, evinced, on the access of atmospheric air, very marked contractions in the right auricle. When that viscus was removed from the body and placed on the glass disk, it lay motionless, but was made to contract strongly again by means of powerful electric shocks. These contractions, however, were exclusively confined to the right auricle, in whatever directions the electric fluid was made to pass through the heart. When the various nerves supplying muscles were excited, convulsions, either in the direction of flexion or extension of the arms and fingers, were excited; and these movements were in keeping with the direction of the fluid and the length of time the contact was continued.

Convulsions of the muscles of the face were attempted to be produced, yet the muscles of mastication remained motionless. The duration of the other muscular contractions never lasted beyond the time of the actual application of the pole, whether the latter was placed in immediate contact with the spinal marrow or not, which circumstance proved that the vitality of the medulla, as a carebral organ, was destroyed, and that it acted merely as a simple conductor of the electric fluid. From this fact it may be deduced, that the bond of connexion between intelligence and the nervous matter had for some time been destroyed. The anatomical investigations were principally directed to the yellow spot of the eye, which is thought to exist during life merely by the effect of light. After an horizontal section of the eye had been made, but a few hours had elapsed, and the spot was noticed to appear in a more and more marked manner; it was found in a similar state in the other eye, which had been preserved 